the greater the risks of prolapse. The author explains the mechanism of prolapse development by the particular position of the sacrosciatic ligament and its looseness at the time of farrowing. This measure is suggested as a means for determining whether a sow should be culled or not.

\title{
Unknown epidemiological aspects of classical swine fever. Consequences on prophylaxis
}

\author{
P. VANNIER (1), E. PLATEAU (2), J. P. TILLON (1) \\ (1) Ministère de l'Agriculture, Direction de la Qualité, Services Vétérinaives \\ Station de Pathologie Porcine, B.P. 9, 22440 Ploufragan (France) \\ (2) Laboratoire Central de Recherches Vétérinaires \\ 22, rue Pierre-Curie, B.P. no 67, 94703 Maisons-Alfort Cedex (France)
}

Two different experiments were carried out with a particular strain of swine fever virus solated from a field case. First, post weaning piglets were infected through the intra muscular toute. Individual susceptibility was prominent in the development of clinical signs and the severity of the disease among post weaning piglets. Duration of hyperthemia ranged from one to nineteen days; $4^{\circ} \mathrm{p}$. I 00 of the animals died, but the survivors were only slightly affected in their final growth rate.

Survivors did not excret the virus more than $26 / 30$ days after inoculation and the virus was not detected in the organs of the animals after slaughter 60 days post infection and later. On the other hand sows were inoculated at different stages of pregnancy with the same strain; no clinical sign was observed in the sows after inoculation and during pregnancy, but a high proportion of piglets exhibited splay-leg, nervous disorders and perinatal mortality. A few piglets from sows inoculated during pregnancy survived and remained inapparent carriers of virus during their whole life without producing antibodies. It was concluded that immunotolerance had been induced in these animals. Transmission of the virus from immunotolerant to susceptible pigs was made by contact five weeks after farrowing, but not after three months in spite of the persistance of the virus at a high concentration in the blood and organs of immunotolerant pigs. These results could explain the appearance on the field of some variantes of the disease and the presence of cases of unknown origin and unexplained epidemiological factors. These particularities and the measures of sanitary prophylaxis necessary for the eradication of the disease are discussed.

\section{I.N.R.A. \\ Epidemiology of pig diseases in connection with intensive production system

\author{
J. P. TILLON \\ Ministère de l'Agriculture, Direction de la Qualité, Services Vétérinaires \\ Station de Pathologie Porcine, B.P. no 9, 22440 Ploufragan (France)
}

\begin{abstract}
After a description of the main pathological cases in connection with intensive pig production, the author describes the modern environmental conditions of pig herds with a special reference to the overall management and productivity imperatives. The pathological manifestations observed should not be interpreted independently as they result from an inadaptation of rearing conditions to production goals. The intervention of the pathologist should therefore lead to a correction of overall management failures. The establishment of a valid " herd diagnosis " requires a co-operation between the pathologist and the other pig production specialists. The development of health control systems is considered.
\end{abstract}

